\title{
Transvaginal excision of rectal stromal tumors: case reports and a literature review
}

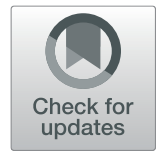

Wang Shizhuo ${ }^{1}$, Liuyuan ${ }^{2}$, Ni Sha ${ }^{1}$, Chen Xueting ${ }^{1}$, Wang He ${ }^{1}$, Luan Nannan ${ }^{1 *}$ and Ma Xiaoxin ${ }^{*}$

\begin{abstract}
Background: Gastrointestinal stromal tumors (GISTs) are the most common mesenchymal tumors of the gastrointestinal tract. Rectal locations are very rare, and minimally invasive surgery is a good choice for the treatment of rectal GISTs.

Case presentation: Two women each had a mass located on the lower vaginal-rectal space as determined by transvaginal ultrasound (TV-US), pelvis MR imaging, and colonoscopy. The patients successfully underwent transvaginal excision. The spindle-shaped cells were found in pathological test. The immunohistochemical analysis showed that CD117 and Dog-1 were stained positively. These results confirmed the masses as GISTs. The postoperative period was uneventful without anal dysfunction. Two patients were received adjuvant treatment with imatinib after surgery.
\end{abstract}

Conclusion: Transvaginal excision could be a minimally invasive and safe alternative treatment in the management of rectal GISTs in lower locations.

Keywords: Rectal GIST, Transvaginal excision, Lower region

\section{Background}

Gastrointestinal stromal tumors (GISTs) are a common type of mesenchymal tumors. The common sites of origination are the stomach $(60-70 \%)$ and intestines $(20-30 \%)[1,2]$. Rectal GISTs are rare. Additionally, a rectal GIST is an extremely rare entity in females [3].

Different surgical methods have been widely reported, including transanal excision, laparoscopic surgery, transsacral excision, and transanal endoscopic microsurgery (TEM) [4-7]. Sometimes, rectal GISTs, especially those located in the lower rectum, are detected upon expansion of the posterior wall of the vagina during a gynecological examination in females. Therefore, we considered transvaginal resection as an alternative treatment because of the vaginal-rectal anatomical location of the tumors in question. Here, we reported two cases of transvaginal excision at Shengjing Hospital during 201-22018 to highlight the clinical and surgical features of lower rectal GISTs.

\footnotetext{
* Correspondence: luannn@sj-hospital.org; luannn@sj-hospital.org ${ }^{1}$ Department of Obstetrics and Gynecology, Shengjing Hospital, China Medical University, 36 San Hao Street, Heping District, Shenyang 110004, Liaoning, China

Full list of author information is available at the end of the article
}

\section{Case presentation}

Case one

A 62-year-old woman, G1P1, was referred to a gynecological doctor for a large "vaginal mass". She did not have abnormal vaginal bleeding but found one vaginal mass by herself 1 month ago. Her age at the beginning of menopause was 52 years old. Her medical and surgical histories were both negative. On gynecological examination, we found that the mass was non-mobile and was $5 \times 5 \mathrm{~cm}^{2}$ in size, with a location of approximately $3 \mathrm{~cm}$ from the vaginal orifice and closely attached to the vaginal wall. On rectal examination, we found that the mass located on the anterior of the rectal wall was approximately $3 \mathrm{~cm}$ from the anal verge. The pelvis $\mathrm{MR}$ scan and transvaginal ultrasound results showed a tumor, $5 \mathrm{~cm}$ in diameter, was mostly located in the space of the rectovaginal septum, with large portion protruding into the vaginal wall but only a small portion protruding into the rectal wall. Its boundary is clear (Fig. 1a, b). Colonoscopy revealed that the root of the tumor was located on the rectal dentate line (Fig. 1c). The origin of the tumor was uncertain. Based on these examinations, the gastrointestinal doctor and us co-evaluated that if we selected a transvaginal resection, we could intactly excised the tumor with less possible complications such as fecal incontinence or anal sphincter dysfunction 


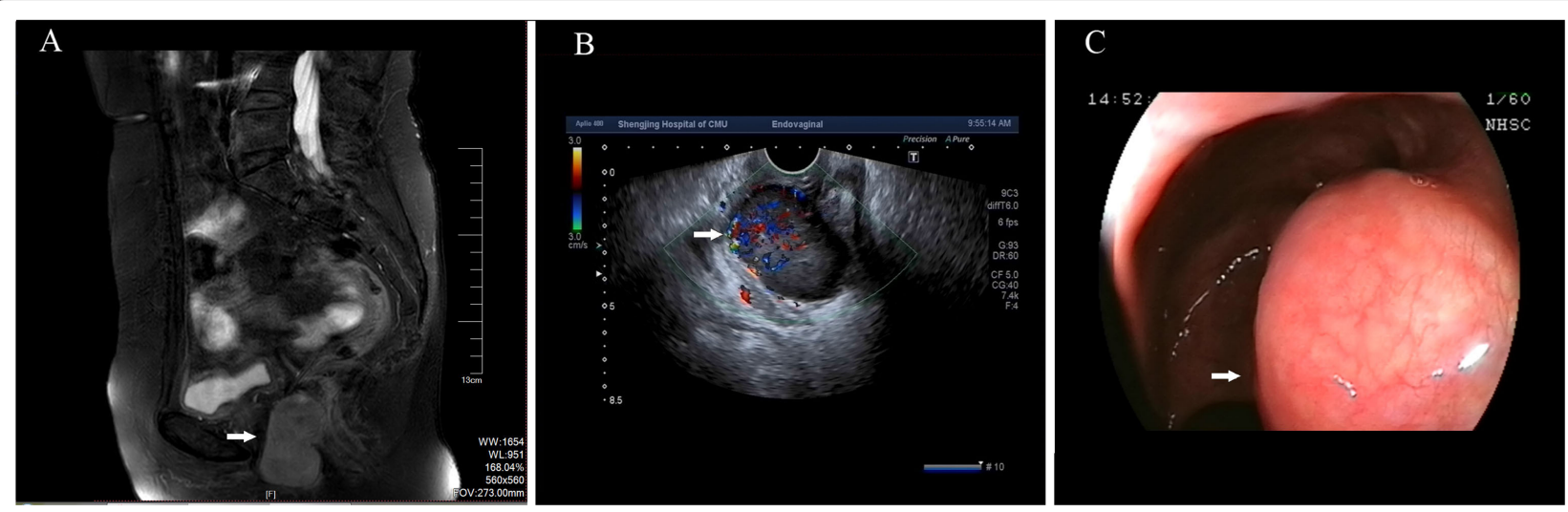

Fig. 1 Imaging examinations show the location of the rectal GISTs. a The results of pelvic MR imaging reveal that the tumor (arrow) was located in the vaginal-rectal space and protruded from the anterior rectal wall. $\mathbf{b}$ The results of transvaginal ultrasound show that the tumor (arrow) protruded from the posterior of the lower vaginal wall. c Colonoscopy results show that the tumor originated from the rectal dentate line

due to its special location. The patient refused to radical anal resection for its anal complications. Therefore, we chose transvaginal resection as a better alternative. Under general anesthesia, the patient was placed in a lithotomy position. Epinephrine, diluted at 1:40,000, was injected into the vaginal submucosa for resection. We incised the vaginal mucosa and separated the surrounding tissue until we reached the submucosa, keeping the tumor capsule intact. After exposing the tumor, we confirmed that it was located in the rectovaginal septum and partially encapsulated by the rectal muscle (Fig. 2a). We mobilized the tumor from the capsule and resected the intact tumor. The defect of rectal muscle was very small but kept the rectal mucosa intact. We vertically stitched the vaginal layers and horizontally stitched the muscular layer of the rectum (Fig. 2b). The postsurgery biopsy showed spindle-
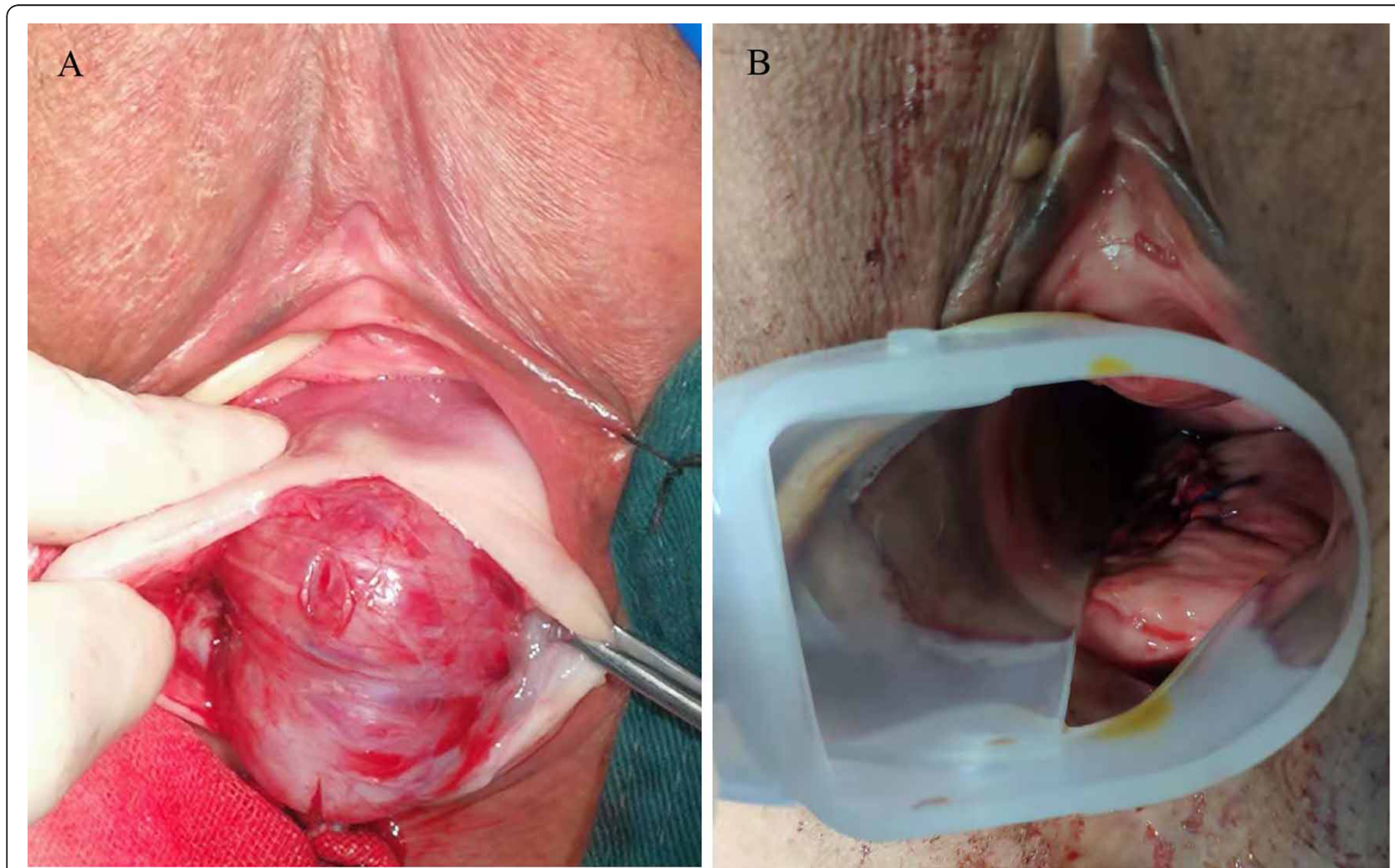

Fig. 2 Transvaginal surgery. a After resection of the posterior vaginal wall, the tumor (arrows) are completely exposed. b After removing the tumor, we stitched the vaginal layers 
shaped cells were moderate differentiation and regular arrangement with clear margin by pathological examination (Fig. 3a, b). The results of histological examination showed that the tumor was positive for CD117, Dog-1, and CD34 (Fig. 3c, e). These findings suggest a moderaterisk rectal GIST that required follow-up. The patient recovered quickly. She had not suffered any anal dysfunction nor postoperative vaginal-rectal fistula. She refused to undergo enlarged resection but received imatinib treatment after surgery. She remained tumor-free for 2 years after surgery. She was lost for follow-up thereafter.

\section{Case two}

We reviewed the relative cases in Shengjing Hospital during 2001-2018. The other GIST patient, a 69-yearold woman with hypertension, was also treated with transvaginal resection. The tumor was $4 \mathrm{~cm}$ in diameter, was located in the vaginal-rectal space and protruded from the lower posterior vaginal wall. On gynecological examination, we found that the mass was fixed and closely attached to the vaginal wall. The results of endoscopic ultrasonography showed that only a small portion of the tumor protruded from the anterior rectal wall (Fig. 4a). Colonoscopy revealed that the root of the tumor was located approximately $3 \mathrm{~cm}$ above the dentate line (Fig. 4b). The results of pelvic MR imaging showed that the tumor was located in the space of the rectovaginal septum and encapsulated by the rectal muscle, with partially unclear boundary to the vaginal wall (Fig. 4c). The ultrasound biopsy showed that some spindle-shaped cells were irregularly arranged. The cells were stained positive for CD117 and Dog-1 (Fig. 5). The results suggested a low-moderate risk rectal GIST. The patient also refused to radical surgery for her old age and possible anal dysfunction. We suggested the patient consider preoperative imatinib treatment, since it may reduce the tumor volume and improve the chances of radical surgery. However, the patient refused preoperative imatinib treatment. At last, we chose a transvaginal resection as an alternative. The surgical method was similar to that described in the previous case (Fig. 6a). During surgery, we found the tumor was a circumscribed rectal submucosal mass with vaginal submucosa invasion. The tumor was intactly excised with the adherent vaginal wall and the rectal mucosa showed only a $2 \times 1.5 \mathrm{~cm}^{2}$ defect. We repaired the defect and stitched all the layers (Fig. 6b). The postoperative course was safe and quick. The patient went back home on the fifth day without any anal dysfunction nor vaginal-rectal fistula. The results of postoperative histological examination showed that the tumor was resected with clear margin (Fig. 6c). They were coherent with the results of preoperative biopsy. The patient recovered quickly. She had not suffered any anal dysfunction nor postoperative vaginal-rectal fistula. She also refused radical resection but received imatinib treatment after surgery. She remained tumor-free for 12 months till now.

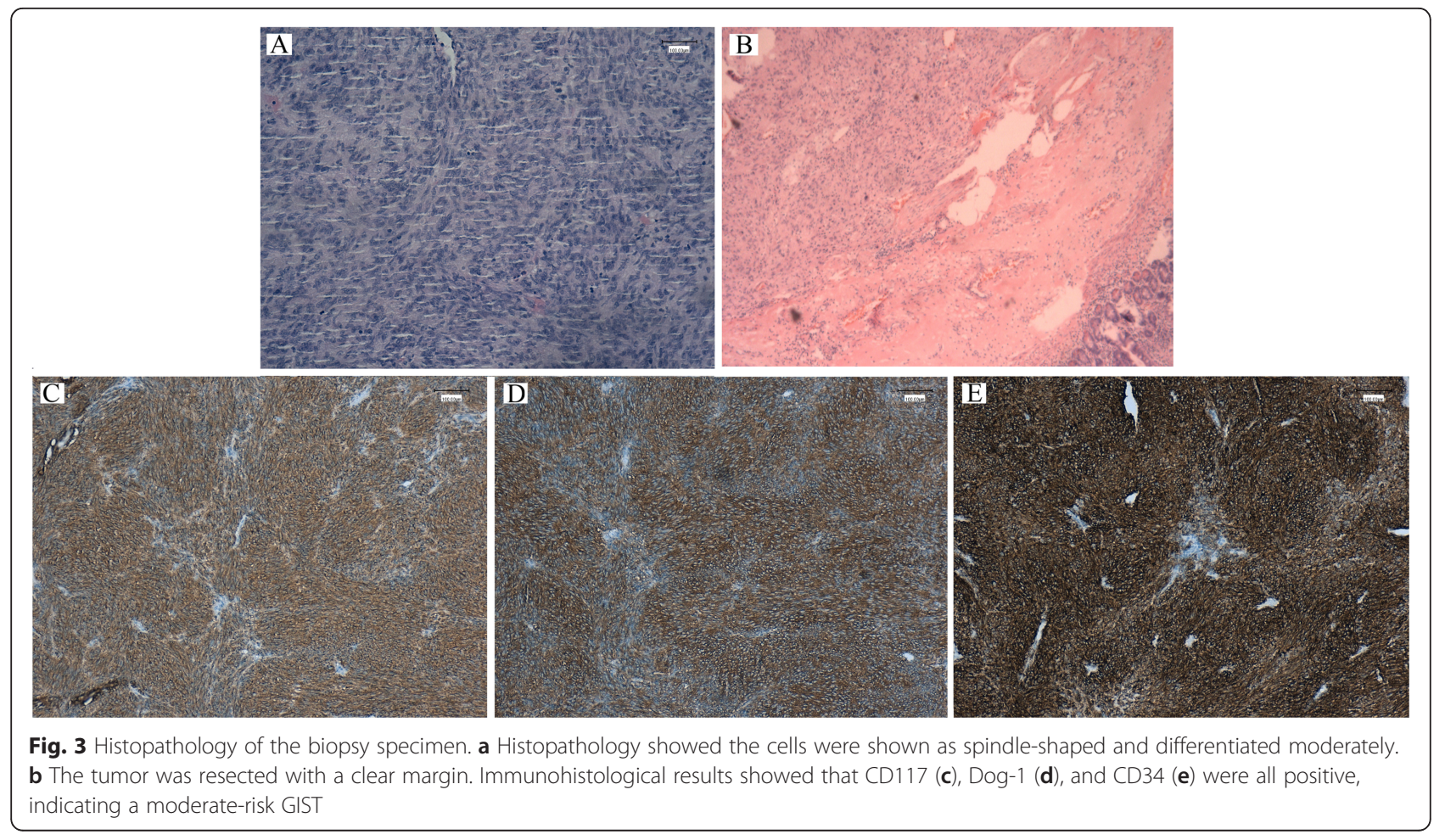




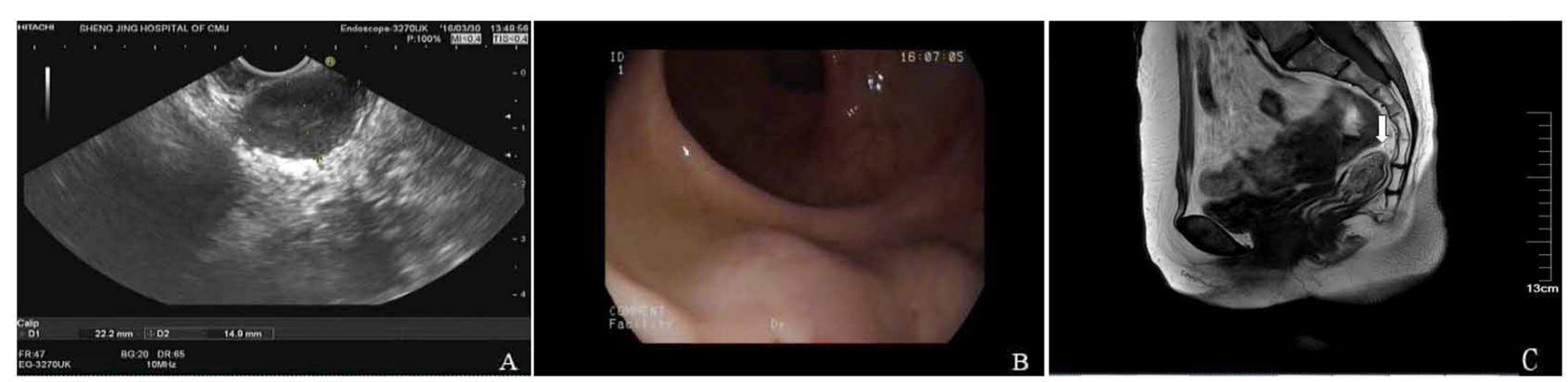

Fig. 4. Imaging examination shows the location of the other rectal GIST. a Endoscopic ultrasonography shows that the tumor protruded from the anterior rectal wall. $\mathbf{b}$ The colonoscopy results show that the root of the tumor was located only $3 \mathrm{~cm}$ above the dentate line. $\mathbf{c}$ The results of MR (arrow) showed that the tumor was located in the space of the rectovaginal septum and encapsulated by the rectal muscle, with partially unclear boundary to the vaginal wall

\section{Discussion}

Intact resection is the best choice for rectal GIST treatment. Radical resection is one of the most important factors for rectal GIST prognosis [8]. However, the surgical procedure for rectal GISTs is difficult and has been debated [9-11]. Most GISTs originate from the muscularis propria and occasionally from the muscularis mucosa [10, 11]. For large rectal GISTs or lower rectal GISTs, radical resection may induce severe anal dysfunction and discomfort. Currently, selecting different surgical procedures for minimally invasive surgery is widely accepted $[11,12]$. Increasing research has shown that minimally invasive surgery, such as transanal endoscopic surgery, could reduce the rate of anal dysfunction [13, 14]. The approach of minimally invasive surgery that we choose for rectal GIST patients depends on the tumor pathology, volume, location, and the surgeon's skills. The most common approach is trans-anal resection. It is suitable for small GISTs located in the distal rectum with limited bowel circumference extension $[15,16]$. Trans-sacral resection and TEM are suitable for tumors located on the posterior wall or in the middle or upper rectal areas [7, 17]. When the tumor is located in lower rectum, with a high risk for metastasis or large volume, we can also consider preoperative imatinib treatment for shrinking tumor volume, improving intact resection, good anal functional, and improving disease-free survival [18-20]. Meanwhile, when the tumor is located in the lower rectal part and its large part was encapsulated by the vaginalrectal septum and protruded into the vaginal wall, we could choose transvaginal resection. There have been few reports discussing the transvaginal resection of rectal GISTs [21, 22]. Hellan et al. first reported that this approach successfully resected larger tumors, sparing the patient from an unnecessary large anal resection [21]. Later, Hara et al. also reported that transvaginal resection of low anterior rectal lesions may provide a minimally invasive alternative to traditional ultra-low anterior resection [22]. In this report, we describe the cases of two successfully resected rectal GISTs located on the anterior rectal wall through a transvaginal procedure. Transvaginal resection is an approach worth considering, as the volume of vagina is large enough to accommodate the resection
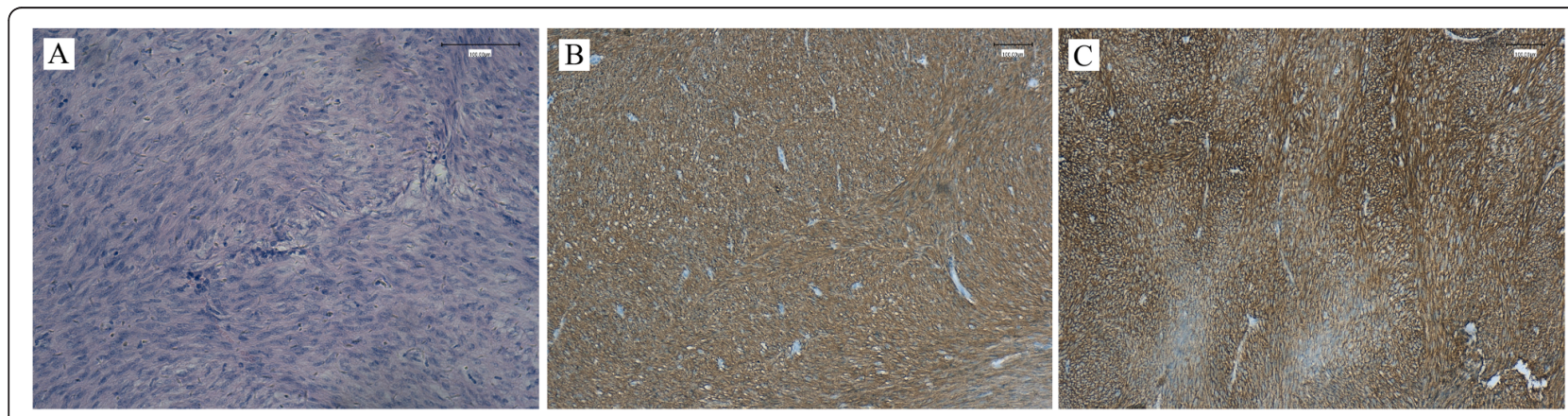

Fig. 5 Histological examination shows that cells were spindle-shaped (a). The specimen was positive for CD117 (b) and Dog-1 (c), indicating a low-moderate risk 

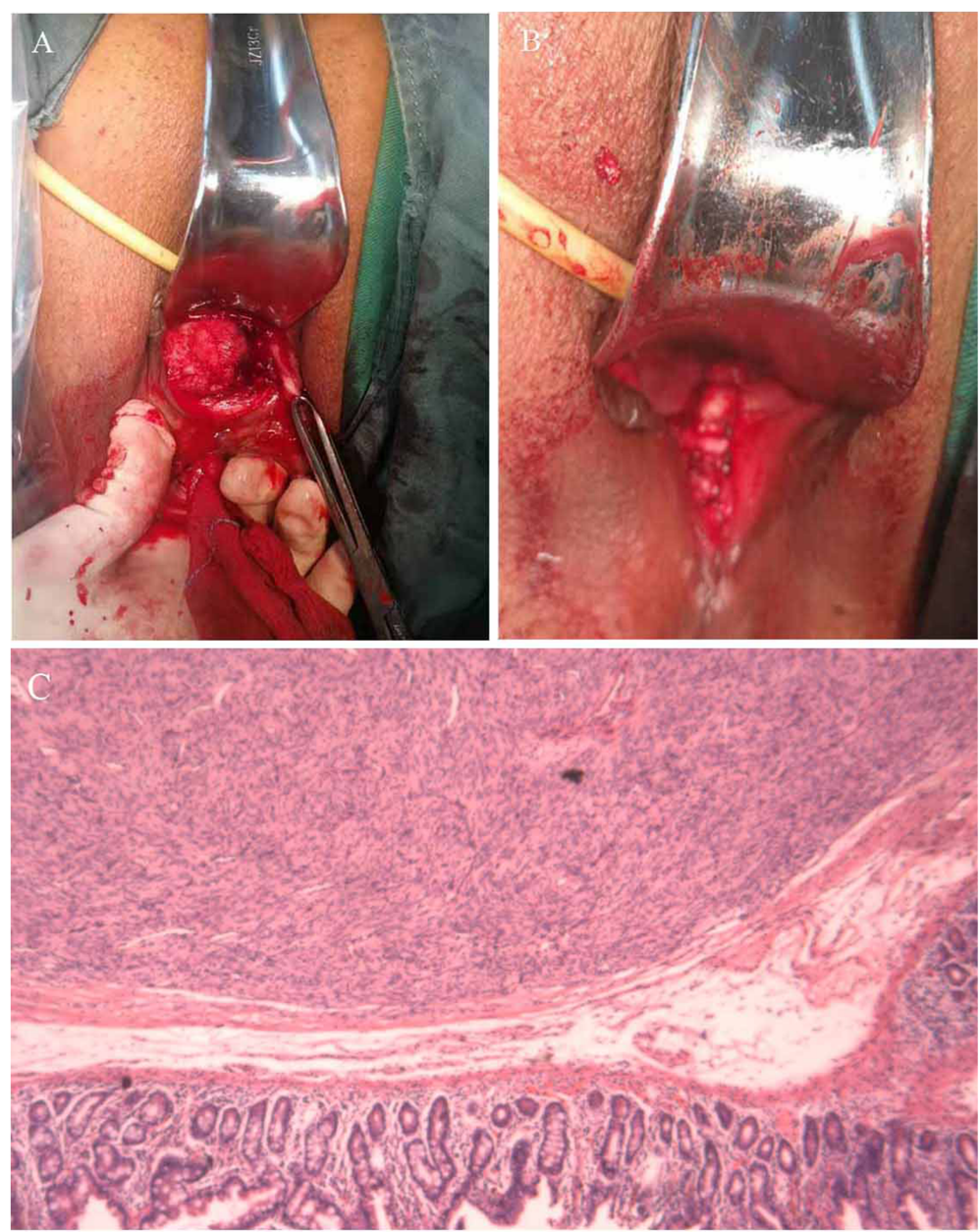

Fig. 6 Transvaginal surgery for the second rectal GIST. a After resection of the posterior vaginal wall, the tumor was completely exposed. b After removing the tumor, we stitched the vaginal layers. The tumor was resected with clear margin (c)

procedure for GISTs. Both of them received postoperative imatinib treatment to prevent recurrence. These two patients failed to receive preoperative imatinib treatment. One patient did not have preoperative biopsy while the other refused to receive. Cavnar et al. reported that as for moderate-high rectal GIST, preoperative imatinib treatment was associated with higher rates of organ preservation, negative margins, and recurrence-free survival [18-20]. One systematic review reported the significance of preoperative imatinib treatment on rectal GIST. Their results showed that the integrated treatments are significant since it could obtain more complete resections and better disease-free and overall survival [23]. Based on these reports, we could suggest lower rectal GIST patients with large volume and special location to attempt transvaginal resection combined with preoperative and postoperative imatinib treatment. These two patients failed to receive preoperative imatinib treatment although the tumors were resected with clear margin. The prognosis for these patients needs to be detected. Two patients should be followed up every 3 months. In summary, we consider the transvaginal approach for rectal GIST tumors as a reasonable surgical procedure.

\section{Conclusion}

Transvaginal excision may be a minimally invasive and safe alternative for the management of rectal GIST in a lower location.

\section{Abbreviations}

GIST: Gastrointestinal stromal tumor; IM: Imatinib mesylate; MR: Magnetic resonance; TEM: Transanal endoscopic microsurgery 


\section{Authors' contributions}

WSZ and LN conducted the surgery, conceived of the study, designed it, and acquired the data. YL in the Gastrointestinal Department, facilitated us conducting the surgery and guided patients on imatinib treatment. NS, CUT, and WH participated in the surgery. WSZ drafted the manuscript. MX guided the surgery and made critical revisions. All authors read and approved the manuscript.

\section{Funding}

No funding

\section{Availability of data and materials}

The data and materials can be made available upon inquiry.

\section{Ethics approval and consent to participate}

Ethics approval was granted by the Shengjing Hospital Ethics Committee.

\section{Consent for publication}

Consent was provided for the publication of images and necessary data.

\section{Competing interests}

The authors declare that they have no competing interests.

\section{Author details}

'Department of Obstetrics and Gynecology, Shengjing Hospital, China Medical University, 36 San Hao Street, Heping District, Shenyang 110004 , Liaoning, China. ${ }^{2}$ Department of Gastrointestinal Department, Shengjing Hospital, China Medical University, 36 San Hao Street, Heping District, Shenyang 110004, Liaoning, China.

Received: 22 May 2019 Accepted: 29 August 2019

Published online: 06 October 2019

\section{References}

1. Miettinen M, Furlong M, Sarlomo-Rikala M, Burke A, Sobin LH, Lasota J. Gastrointestinal stromal tumors, intramural leiomyomas, and leiomyosarcomas in the rectum and anus: a clinicopathologic immunohistochemical, and molecular genetic study of 144 cases. Am J Surg Pathol. 2001;25(9):1121-33.

2. Tran T, Davila JA, El-Serag HB. The epidemiology of malignant gastrointestinal stromal tumors: an analysis of 1,458 cases from 1992 to 2000. Am J Gastroenterol. 2005;100(1):162-8.

3. Wilkinson MJ, Fitzgerald JE, Strauss DC, Hayes AJ, Thomas JM, Messiou C, Fisher C, Benson C, Tekkis PP, Judson I. Surgical treatment of gastrointestinal stromal tumour of the rectum in the era of imatinib. $\mathrm{Br}$ J Surg. 2015;102(8):965-71.

4. Centonze D, Pulvirenti E, Pulvirenti D'Urso A, Franco S, Cinardi N, Giannone G. Local excision with adjuvant imatinib therapy for anorectal gastrointestinal stromal tumors. Tech Coloproctol. 2013;17:571-4.

5. Quaresima S, Balla A, Franceschilli L, La Torre M, lafrate C, Shalaby M, Di Lorenzo N, Sileri P. Transanal minimally invasive surgery for rectal lesions. J Soc Laparoendosc Surg. 2016;20(3):e2016.00032.

6. Kyo K, Azuma M, Okamoto K, Nishiyama M, Shimamura T, Maema A, Kanamaru H, Shirakawa M, Nakamura T, Shinmura K, Koda K, Yokoyama H. Neoadjuvant imatinib treatment and laparoscopic anus-preserving surgery for a large gastrointestinal stromal tumor of the rectum. World J Surg Oncol. 2016:14:68.

7. Gervaz P, Huber O, Bucher P, Sappino P, Morel P. Trans-sacral (Kraske) approach for gastrointestinal stromal tumour of the lower rectum: old procedure for a new disease. Color Dis. 2008;10(9):951-2.

8. Blackstein ME, Dubé $P$, Fletcher JA, Keller OR, Knowling M, Létourneau R, Morris D, Riddell R, Rorke S, Swallow CJ. Gastrointestinal stromal tumours: etiology, pathology and clinical management. Can J Gastroenterol Hepatol. 2004;18(Suppl B):3B-8B.

9. Keller DS, Tahilramani RN, Flores-Gonzalez JR, Mahmood A, Haas EM. Transanal minimally invasive surgery: review of indications and outcomes from 75 consecutive patients. J Am Coll Surg. 2016;222(5):814-22.

10. Liu Q, Zhong G, Zhou W, Lin G. Initial application of transanal endoscopic microsurgery for high-risk lower rectal gastrointestinal stromal tumor after imatinib mesylate neoadjuvant chemotherapy: a case report. Medicine (Baltimore). 2017;96(29):e7538.
11. Marcella C, Shi RH, Sarwar S. Clinical overview of GIST and its latest management by endoscopic resection in upper Gl: a literature review. Gastroenterol Res Pract. 2018;2018:6864256.

12. Somu K, Dashore AR, Shah AR, Anandh R. Laparoscopic excision of large lower rectal gastrointestinal stromal tumour (GIST): A case report. J Minim Access Surg. 2016;12(3):283-5.

13. Nepal P, Mori S, Kita Y, Tanabe K, Baba K, Uchikado Y, Kurahara H, Arigami T, Sakoda M, Maemura K, Natsugoe S. Management of a case of high-risk gastrointestinal stromal tumor in rectum by transanal minimal invasive surgery. World J Surg Oncol. 2018;16(1):165.

14. Arezzo A, Verra M, Morino M. Transanal endoscopic microsurgery after neoadjuvant therapy for rectal GIST. Dig Liver Dis. 2011;43(11):923-4.

15. WJ K, Friel CM. Diagnosis and treatment of rectal gastrointestinal stromal tumors. Dis Colon Rectum. 2019;62(5):537-40.

16. Liu H, Yan Z, Liao G, Yin H. Treatment strategy of rectal gastrointestinal stromal tumor (GIST). J Surg Oncol. 2014;109:708-13.

17. Christoforidis D, Cho HM, Dixon MR, Mellgren AF, Madoff RD, Finne CO. Transanal endoscopic microsurgery versus conventional transanal excision for patients with early rectal cancer. Ann Surg. 2009;249(5):776-82.

18. Cavnar MJ, Wang L, Balachandran VP, Antonescu CR, Tap WD, Keohan M, Singer S, Temple L, Nash GM, Weiser MR, Guillem JG, Aguilar JG, DeMatteo RP, Paty PB. Rectal gastrointestinal stromal tumor (GIST) in the era of imatinib: organ preservation and improved oncologic outcome. Ann Surg Oncol. 2017;24(13):3972-80.

19. McCarter MD, Antonescu CR, Ballman KV, Maki RG, Pisters PW, Demetri GD, Blanke CD, von Mehren M, Brennan MF, McCall L, Ota DM, De Matteo RP, American College of Surgeons Oncology Group (ACOSOG) Intergroup Adjuvant Gist Study Team. Microscopically positive margins for primary gastrointestinal stromal tumors: analysis of risk factors and tumour recurrence. J Am Coll Surg. 2012;215(1):53-9 discussion 59-60.

20. Cohen NA, Kim TS, DeMatteo RP. Principles of kinase inhibitor therapy for solid tumors. Ann Surg. 2017;265(2):311-9.

21. Hellan M, Maker VK. Transvaginal excision of a large rectal stromal tumor: an alternative. Am J Surg. 2006;191(1):121-3.

22. Hara M, Takayama S, Arakawa A, Sato M, Nagasaki T, Takeyama H. Transvaginal resection of a rectal gastrointestinal stromal tumor. Surg Today. 2012:42(9):909-12

23. Cirocchi R, Farinella E, La Mura F, Cavaliere D, Avenia N, Verdecchia GM, Giustozzi G, Noya G, Sciannameo F. Efficacy of surgery and imatinib mesylate in the treatment of advanced gastrointestinal stromal tumor: a systematic review. Tumori. 2010;96(3):392-9.

\section{Publisher's Note}

Springer Nature remains neutral with regard to jurisdictional claims in published maps and institutional affiliations.

Ready to submit your research? Choose BMC and benefit from:

- fast, convenient online submission

- thorough peer review by experienced researchers in your field

- rapid publication on acceptance

- support for research data, including large and complex data types

- gold Open Access which fosters wider collaboration and increased citations

- maximum visibility for your research: over $100 \mathrm{M}$ website views per year

At $\mathrm{BMC}$, research is always in progress.

Learn more biomedcentral.com/submission 